\title{
A Lente da Fenomenologia de Merleau-Ponty para a Psicopatologia Cultural ${ }^{1}$
}

\author{
Thabata Castelo Branco Telles \\ Virginia Moreira ${ }^{2}$ \\ Universidade de Fortaleza
}

\begin{abstract}
RESUMO - Este artigo tem o objetivo de apontar contribuições da fenomenologia de Merleau-Ponty para a psicopatologia cultural. Discutimos alguns temas presentes nessa filosofia associados a ideias contidas nas pesquisas recentes em psicopatologia cultural, tais como corpo, liberdade, linguagem, arte e cultura. Destacamos a discussão realizada por Merleau-Ponty acerca das obras do pintor Paul Cézanne como contribuição para um novo olhar sobre a psicopatologia cultural, ressaltando a ambiguidade presente nos processos de adoecimento e nas distintas nuanças que se entrelaçam na experiência vivida de sofrimento.
\end{abstract}

Palavras-chave: fenomenologia, Merleau-Ponty, psicopatologia cultural

\section{The Merleau-Ponty's Phenomenology Lens to Cultural Psychopathology}

\begin{abstract}
This paper aims to present contributions of Merleau-Ponty's phenomenology to cultural psychopathology. We discuss some themes of this philosophy associated to ideas presented in recent studies in the field of cultural psychopathology such as body, freedom, language, art, and culture. We highlight the discussion found in Merleau-Ponty's phenomenology about Paul Cézanne's paintings, as a contribution to a new outlook to cultural psychopathology, which considers the ambiguity in illness processes and in nuances which are intertwined in lived experience of suffering.
\end{abstract}

Keywords: phenomenology, Merleau-Ponty, cultural psychopathology

Entendemos a psicopatologia cultural como uma área que contempla estudos em psicologia, psiquiatria, antropologia, e demais áreas do saber, que convergem em pesquisas concernentes às relações entre questões culturais e psicopatologia. Como nos lembra Kirmayer (2006), toda experiência humana é culturalmente constituída. Assim, é impossível a compreensão da psicopatologia sem considerarmos os aspectos culturais que a atravessam.

López e Guarnaccia (2000) problematizam o diagnóstico nos manuais psiquiátricos, esclarecendo que as categorias neles contidas eram universalizantes, desconsiderando a importância da cultura na compreensão dos distintos quadros de transtornos mentais. Houve um forte movimento para que essas categorias psicopatológicas fossem mais contextualizadas, principalmente por parte de alguns psiquiatras que já realizavam pesquisas na área de antropologia médica e psiquiatria cultural, em instituições como Harvard, nos Estados Unidos, e McGill, no Canadá. Também, é relevante destacarmos o enfoque da etnopsiquiatria, iniciado com Georges Devereux (1977), na França. Com o lançamento do DSM - IV (APA, 2000), foi a primeira vez que um manual psiquiátrico atentou para a cultura como fundamento importante no processo de diagnóstico das doenças mentais, porém, de forma sutil (López \& Guarnaccia, 2000).

Na década de 1970, é publicada a obra mais marcante de Georges Devereux (1977), Essais d'ethnopsychiatrie

1 Apoio: FUNCAP

2 Endereço para correspondência: APHETO, Laboratório de Psicopatologia e Psicoterapia Humanista Fenomenológica Crítica, Universidade de Fortaleza, Avenida Washington Soares, $n^{\circ}$ 1321, Edson Queiroz, Fortaleza, CE, Brasil. CEP: 60811-905.E-mail: thabata@ gmail.com générale, que já apontava para a necessidade do papel da cultura nos processos psicopatológicos ser repensado. Em 1985, é lançado o livro Culture and Depression, por Arthur Kleinman e Byron Good, obra que também problematiza a psicopatologia - no caso desse livro, especificamente, a depressão -, a partir da cultura. No entanto, de acordo com López e Guarnaccia (2000), é somente no livro Rethinking Psychiatry, lançado pelo psiquiatra e antropólogo Arthur Kleinman (1988a) que primeiramente, podemos reconhecer que a cultura importa para o estudo e o tratamento das psicopatologias. A obra de Kleinman pode ser considerada clássica por discutir pesquisas na área realizadas por antropólogos, psicólogos e psiquiatras. Ela faz um chamado a todos aqueles que trabalham com psicopatologia, para que as formas de prevenção e de tratamento das doenças mentais sejam repensadas, uma vez que é imprescindível que o contexto cultural em que elas estão inseridas seja compreendido.

Kleinman (1988b) define três diferentes concepções de doença, que, por não terem tradução exata para a língua portuguesa, manteremos, aqui, suas definições no idioma original, o inglês:

- Disease: é a forma de compreensão da doença mental que encontramos mais comumente nos manuais de diagnóstico psiquiátrico, sendo ela pensada a partir de sua sintomatologia, do ponto de vista biomédico;

- Illness: além de adotar características sintomatológicas, esta definição de doença mental considera e foca a compreensão do sofrimento dos pacientes, a experiência vivida deles, na perspectiva deles; e 
- Sickness: é o modo como a sociedade compreende as psicopatologias, contemplando o senso comum, referindo-se à família e à comunidade em que o paciente está inserido.

Essa diferenciação é importante na medida em que ressalta as diferentes nuanças a partir das quais um mesmo processo psicopatológico pode ser compreendido. São compreensões que merecem ser, conjuntamente, consideradas na prevenção e no tratamento dos distintos quadros psicopatológicos. Kleinman (1988a) propõe que "um modelo mais útil é onde processos biológicos e culturais interajam dialeticamente ${ }^{1}$ " (p. 25), criticando, assim, a hegemonia do pensamento biológico na etiologia das doenças mentais, ao possibilitar uma compreensão menos dicotomizada para a psicopatologia cultural. Além dessa proposta de interação das questões biológicas e culturais, Kleinman e Good (1985) propõem a compreensão da cultura na intersecção entre significado e experiência. Ou seja, trata-se de compreender a cultura levando em consideração tanto seu significado atribuído quanto as experiências vividas.

Poucos pesquisadores (Csordas, 1990, 1993, 2008; Felder \& Robbins, 2011; Moreira \& Sloan, 2002; Moreira, 2009; Sam \& Moreira, 2012) propuseram-se a discutir a psicopatologia cultural sob a perspectiva da fenomenologia de Merleau-Ponty (1945/2000, 1948/1996, 1955/2006, 1961/2004, 1964/2007, 2001/2010, 1969/2010). Trata-se de perspectiva ainda pouco desenvolvida, principalmente no Brasil. Este artigo tem como objetivo discutir as contribuições da fenomenologia de Merleau-Ponty (1945/2000, 1948/1996, 1955/2006, 1961/2004, 1964/2007, 2001/2010, 1969/2010) para a psicopatologia cultural.

\section{Considerações sobre a fenomenologia de Merleau- Ponty}

Maurice Merleau-Ponty foi um filósofo francês, que viveu de 1908 a 1961. Pode ser considerado um filósofo que retomou e deu continuidade à fenomenologia de Edmund Husserl (Moreira, 2010; Tatossian \& Moreira, 2012), que fora, por sua vez, precursor da noção de Lebenswelt (mundo vivido) (Husserl, 1954/1976). Entretanto, a fenomenologia de Merleau-Ponty é marcada pela ambiguidade, em uma radical superação das dualidades - tais como interior-exterior, subjetivismo-objetivismo, natural-cultural (Matthews, 2010). Essa questão é fundamental para que possamos compreender a noção de homem em Merleau-Ponty, rumo a um aprofundamento da entrelaçada relação entre psicopatologia e cultura. Através de nota publicada postumamente, o filósofo argumentava que "a distinção dos dois planos (natural e cultural) é, aliás, abstrata: tudo é cultural em nós (o nosso Lebenswelt é 'subjetivo') (a nossa percepção é culturalhistórica) e tudo é natural em nós (mesmo o cultural repousa sobre o polimorfismo do Ser selvagem)" (Merleau-Ponty, 1964/2007, p. 229). Nesse sentido, somente é possível compreender a cultura na fenomenologia de Merleau-Ponty a partir da ambiguidade, dado que, ao mesmo tempo, tudo

1 "A more useful model is one in which biological and cultural processes dialectically interact" (Tradução livre das autoras). é natural e tudo é cultural em nós, de modo que não há uma distinção nítida de natureza e cultura na experiência vivida.

A filosofia de Merleau-Ponty compreende o homem a partir de sua facticidade, ou seja, da sua existência concreta no mundo (Merleau-Ponty, 1945/2000). Trata-se de uma compreensão da experiência desvinculada de uma essência pura, mas que se manifesta na fissão do tecido do mundo (Dupont, 2010). Acerca dessa questão, Merleau-Ponty comenta que

este mundo, que parece estar sem mim, que me cerca e me ultrapassa, sou eu quem o faz. Sou então uma consciência, uma presença imediata ao mundo, que não há nada que possa pretender ser sem ser tomada de qualquer maneira dentro do tecido da minha experiência (Merleau-Ponty, 1948/1996, p. 38).

Essa relação entre homem e mundo encontra-se, na fenomenologia de Merleau-Ponty, atravessada pela noção de corpo. O corpo é o que nos coloca em situação, o que nos abre e nos fecha ao mundo. É o local da experiência vivida e do entrelaçamento entre natureza e cultura. Portanto, apresentase como espaço de superação de dualidades, uma vez que é aí que nos situamos, numa relação ambígua. Merleau-Ponty afirma que,

mas, justamente porque pode fechar-se ao mundo, meu corpo é também aquilo que me abre ao mundo e nele me põe em situação. O movimento da existência em direção ao outro, em direção ao futuro, em direção ao mundo pode recomeçar, assim como um rio degela (Merleau-Ponty, $1945 / 2000$, p. 228).

O corpo se engaja em uma situação, sempre histórica e espacial, entrelaçada ao mundo e à cultura. É o que nos abre e nos fecha ao mundo e ao outro. A partir desta noção de corpo, podemos ressaltar as noções de intersubjetividade e de intercorporeidade, desenvolvidas ao longo da fenomenologia de Merleau-Ponty. De acordo com Coelho Jr. (2003), a intersubjetividade é marcada por uma quase indiferenciação entre mim e outro, enquanto que, na intercorporeidade, podemos afirmar que há uma radicalidade nessa relação, pois estamos inscritos no mundo (Merleau-Ponty, 1964/2007). Em uma compreensão da intercorporeidade a partir desse viés, o outro se insere na relação entre nós e o mundo, permitindo o reconhecimento da unidade e da diferença entre nós (Alvim, 2011). É o outro que, ambiguamente, nos possibilita a percepção do que é universal e do que é particular em nós.

Diante dessa teia de relações na experiência humana, Merleau-Ponty (1945/2000) discute a liberdade, pensada a partir do engajamento do homem no mundo, uma vez que homem e mundo se constituem mutuamente. No tocante à liberdade, é relevante assinalar que, para Merleau-Ponty, sua realização nunca se manifesta na sua totalidade, ou seja, a partir de sua fenomenologia, é impossível pensar uma liberdade plena ou incondicionada; ela é sempre compreendida a partir de um campo de possibilidades (Dupont, 2010), pois, como define Merleau-Ponty, 
se há uma liberdade verdadeira, só pode ser no curso da vida, pela superação de nossa situação de partida, mas sem que deixemos de ser o mesmo - esse é o problema. Duas coisas são certas a propósito da liberdade: que nunca somos determinados e que nunca mudamos, retrospectivamente poderemos sempre descobrir em nosso passado o anúncio daquilo que nos tornamos. Cabe a nós compreender as duas coisas ao mesmo tempo e de que maneira a liberdade se manifesta em nós sem romper nossos vínculos com o mundo. (Merleau-Ponty, 1961/2004, p. 137-138).

A noção de liberdade em Merleau-Ponty (1945/2000) está sempre engajada em uma situação. Como está atrelada à condição mundana do homem, apenas se manifesta a partir do enraizamento dele no mundo, na história, na sociedade e na cultura. Nesse sentido, discutir a liberdade implica, ainda, em considerar a sua ausência, sua impossibilidade e aquilo que a limita. Ambiguamente, a liberdade sempre está limitada: ao mesmo tempo em que há liberdade, ela apresenta limites e impossibilidades (Moreira \& Telles, 2012).

A linguagem, também, é tema bastante presente na fenomenologia de Merleau-Ponty (1945/2000, 1969/2010, 2001/2006), podendo ser compreendida, ambiguamente, a partir da noção de expressão, que, segundo ele, é uma tarefa infinita, nunca realizada plenamente. Para Merleau-Ponty (1945/2000), como objeto cultural, a linguagem desempenha papel fundamental na percepção do outro. É através dela que se ultrapassa o dualismo entre sujeito e objeto, como o filósofo afirma:

uma vez feita a operação categorial, resta explicar a aparição da palavra que a conclui, e é mais uma vez por um mecanismo fisiológico ou psíquico que se fará isso, já que a palavra é um invólucro inerte. Portanto, ultrapassa-se tanto o intelectualismo quanto o empirismo pela simples observação de que "a palavra tem um sentido". (Merleau-Ponty, 1945/2000, p. 241).

Ou seja, na medida em que, objetivamente, comunicamos algo ao outro, esta comunicação inclui seu aspecto subjetivo por ser atravessada por variadas significações, tanto através das experiências mundanas vividas daquele que fala, quanto por parte daquele que escuta. Nesse sentido, o que se fala será sempre diferente do que se escuta - o encontro acontece no intocável. Essa impossibilidade de completa compreensão da linguagem encontra-se marcada pela existência humana enraizada no mundo, nos permitindo perceber que sempre há algo de particular e de universal em nós. Com relação à cultura, Merleau-Ponty (2001/2006) afirma que ela é um meio, um mediador entre a vida psíquica e a vida coletiva. Para o filósofo, apenas é possível pensar a cultura na experiência, espaço em que os sujeitos se inserem no todo (Merleau-Ponty, 1969/2010).

\section{Uma lente de múltiplos contornos para a psicopatologia inspirada nas pinturas de Paul Cézanne}

A relação entre homem e mundo foi explorada por Merleau-Ponty (1945/2000, 1948/1996, 1955/2006, 1961/2004, 1964/2007, 2001/2010,1969/2010) através das pinturas de Paul Cézanne, pintor francês, que viveu em Aix-en-Provence, na França, de 1839 a 1906. É considerado o precursor do pós-impressionismo, por romper com os enquadres impressionistas, que continham contornos nítidos nas pinturas. A obra de Cézanne caracteriza-se por distorcer, formalmente, a imagem para enfatizar, através da cor, o peso e o volume dos objetos, sem contornos nítidos (Becks-Malorny, 2007). A pintura de Cézanne serviu de inspiração para diversos escritos de Merleau-Ponty (1945/2000, 1948/1996), devido ao modo como ele realizava os traços em seus quadros - sempre presentes, mas nunca rigidamente nítidos. Ainda que a referência à obra do pintor já se encontre presente em A Fenomenologia da Percepção (Merleau-Ponty, 1945/2000) é a obra Sens et Non-Sens ${ }^{2}$ (Merleau-Ponty, 1948/1996), que contém o texto intitulado A Dúvida de Cézanne, escrito em 1945, na qual o filósofo comenta a vida e a obra de Cézanne; nesse texto, a mútua constituição entre homem e mundo é ilustrada por Merleau-Ponty, a partir da explanação da implicação entre sua fenomenologia mundana e as obras do pintor. Cézanne suprimia os contornos precisos na pintura, criando uma preponderância da cor sobre o desenho, que se fazia na medida em que pintava, assim como em nossas experiências, que não são vividas de antemão, mas no movimento entre nós e o mundo.

O grande mote da pintura de Cézanne, de acordo com Merleau-Ponty (1948/1996), é "fazer ver o mundo como ele nos toca"3 (p. 25). Trata-se de compreender a relação entre homem e mundo a partir do engajamento, de uma tomada de posição no mundo. Implicado nos quadros do pós-impressionista, o filósofo assim dissertava acerca da percepção, que apenas pode ser compreendida a partir da experiência: "quando eu percebo, eu não penso no mundo, ele se organiza diante de mim"4 (Merleau-Ponty, 1948/1996, p. 65). Assim como na pintura de Cézanne, nossa experiência emerge a partir de um campo perceptivo. Para que possamos compreender a implicação de Merleau-Ponty nos quadros de Paul Cézanne, é necessário considerar a noção de percepção, amplamente discutida pelo filósofo na sua obra $A$ Fenomenologia da Percepção (Merleau-Ponty, 1945/2000). $\mathrm{O}$ ato da percepção se manifesta somente na experiência, enraizada no mundo, como um golpe, não correspondendo a um ato puramente intelectual. Merleau-Ponty afirmava que o pintor não exprimia algo a partir da pintura, mas pensava através dela. Complementava que, "pensando bem, o mundo está ao redor de mim, não diante de mim [...] Não se trata mais de falar do espaço e da luz, mas de fazer falarem o espaço e a luz que estão aí" (Merleau-Ponty, 1961/2004, p. 33).

Merleau-Ponty (1948/1996) diferencia a fotografia da pintura de Cézanne, sendo esta mais real do que aquela, na medida em que é sempre movimento (Moreira, 2009). A pintura de Cézanne não utilizava uma perspectiva

2 As obras cujos nomes estão em francês consistem em textos lidos no idioma original, sem a tradução para o português.

3 "Faire voir comment il nous touche" (Tradução livre das autoras).

4 "Quand je perçois, je ne pense pas le monde, il s'organise devant moi" (Tradução livre das autoras). 
geométrica, mas vivida, concebida a partir da percepção da nossa existência concreta e enraizada no mundo. A pintura de Cézanne supera a necessidade dos enquadres geométricos, ao utilizar a cor para dar forma, profundidade e perspectiva aos seus objetos. Em A Dúvida de Cézanne, Merleau-Ponty (1948/1996) explicitou essa ideia, afirmando que

não marcar nenhum contorno seria retirar aos objetos sua identidade. Marcar um só seria sacrificar a profundidade, isto é, dimensão que nos oferece a coisa, não como exposta diante de nós, mas como cheia de reservas e como uma realidade inesgotável. Eis porque Cézanne acompanhará, numa modulação de cores, a intumescência do objeto e marcará com traços azuis vários contornos 5 . (Merleau-Ponty, 1948/1996, p. 20).

Na concepção de Merleau-Ponty, há contornos nos quadros de Cézanne, pois há uma divisão entre o homem ou o objeto pintado e as outras partes do quadro, mas não um contorno preciso, bem definido. Moreira (2009) propõe pensarmos estes múltiplos contornos das pinceladas de Cézanne como uma referência à cultura, à sociedade, à história e à ideologia, dentre outros contornos que perpassam a existência humana - e a psicopatologia, no caso mais específico deste trabalho. Nos quadros de Cézanne, há contornos, mas pouco nítidos, o que nos permite considerar que há movimento. Analogamente, na relação entre homem e mundo, em um viés baseado na fenomenologia de Merleau-Ponty, os contornos da cultura, da sociedade, da história e da política, dentre outros, podem ser distinguidos e compreendidos, mas não nitidamente, uma vez que apenas se manifestam no fazer incessante entre homem e mundo, nunca de modo estático. São questões que emergem de forma opaca, através da experiência vivida, enraizada no mundo.

A partir dessa ideia, Moreira (2009) desenvolve uma contribuição para a vertente humanista-fenomenológica da clínica psicológica, discutindo as psicopatologias a partir da lente de Merleau-Ponty (1945/2000, 1948/1996, 1964/2004, 1964/2007), com a implicação entre sua filosofia e os quadros de Cézanne, tal como o filósofo a apresenta em sua obra. Com a noção de múltiplos contornos, destaca, através desta lente, um movimento contínuo entre real e imaginário. Podemos observar, tanto nas pinturas de Cézanne, quanto nos textos de Merleau-Ponty (1945/2000, 1948/1996, 1964/2004, $1964 / 2007)$, um constante movimento na realidade, sempre deformada e opaca. Há algo que é real e algo que é imaginário, ambiguamente, sem uma demarcação nítida.

A partir dessa ausência de uma divisão rígida entre real e imaginário, podemos pensar o movimento saudável como movimento constante na existência humana e diferenciar o que chamamos de psicose e neurose contemporâneas. Compreendemos o psicótico como aquele que apresenta ausência de contorno com a realidade e que, no momento

5 "Ne marquer aucun contour, ce serait enlever aux objets leur identité. En marquer un seul, ce serait sacrifier la profondeur, c'est-à-dire la dimension qui nous donne la chose, non comme étalée devant nous, mais comme pleine de resérves et comme une réalité inépuisable. C'est pourquoi Cézanne suivra dans une modulation colorée le renflement de l'objet et marquer en trait bleus plusieurs contours" (Tradução livre das autoras). do surto psicótico, vivencia, somente, ou de forma preponderante, o imaginário. Por sua vez, o neurótico contemporâneo pode ser considerado alguém que acredita em uma existência puramente real, verdadeira, exata, com contornos rígidos, "experienciando uma rigidez do contorno homem-mundo" (Moreira, 2009, p. 99), como em uma fotografia, ausente de movimentos.

A partir dessa distinção entre o psicótico e o neurótico contemporâneos, proposta por Moreira (2009), discutimos como pode ser pensado um homem saudável com base em tal concepção. A psicopatologia pode ser considerada uma "existência estancada", seja no puro imaginário, seja na rigidez de contornos, não permitindo um "movimento de construção da existência cotidiana" (p. 102). Nesse sentido, é interessante resgatar a definição de psicopatologia de Tatossian (2001), de que "um comportamento ou uma vivência são patológicos quando o-sujeito-não-pode-nãoapresentar este comportamento, ou não-pode-não-apresentaresta-vivência" (p. 144). Ou seja, uma experiência saudável pode ser entendida como aquela que permite os movimentos de existência cotidiana, atravessados por múltiplos contornos imprecisos, e que não estanca em um único modo de existência. Por sua vez, a experiência psicopatológica seria ficar sem contornos, ou quando está restrita a um único contorno, sem que outro fenômeno possa-ser-vivido.

No tocante à perspectiva de Moreira (2009), ao se referir ao texto A Dúvida de Cézanne, de Merleau-Ponty (1948/1996), podemos destacar, como contribuição dela, a utilização da metáfora dos quadros de Cézanne para a elaboração de uma concepção de psicopatologia cultural, pensada a partir dos múltiplos contornos que constituem o homem. Desse modo, a relação entre psicopatologia e cultura assume o movimento e as cores existentes do homem e do mundo, da cultura, da psicopatologia, da ideologia, da sociedade, da fisiologia, por exemplo.

Portanto, uma lente de compreensão fenomenológica da psicopatologia aponta para a necessidade de assumir o movimento cotidiano e ambíguo que aponta Merleau-Ponty (1948/1996), ao tratar dos quadros de Paul Cézanne. Longe de uma tentativa de se inserir em categorias nosológicas, essa lente remonta à experiência vivida e faz perceber que podemos sair de uma reprodução narrativa massificada, rumo a um movimento que resgate o que há de mais primordial em nós: o entrelaçamento com o mundo.

\section{A lente da fenomenologia de Merleau-Ponty para a psicopatologia cultural}

A cultura, para Merleau-Ponty, é percebida e vivenciada no mundo, a partir das distintas experiências vividas em uma sociedade. De acordo com o filósofo, "a cultura pode ser definida como o conjunto das atitudes tacitamente recomendadas pela sociedade ou pelos diferentes grupos nos quais vivemos, atitudes que estão inscritas na ordem material de nossa civilização" (Merleau-Ponty, 2001/2006, p. 377). É, portanto, um espaço que media o indivíduo e a coletividade. Conforme discutimos anteriormente, a cultura é um espaço de ambiguidade entre interior e exterior, indivíduo e coletivo etc., uma vez que um pólo não existe sem o outro. 
Devemos ressaltar a relação ambígua entre natureza e cultura. Merleau-Ponty (1955/2006) toma como exemplo o ato de dormir e se questiona acerca da possibilidade de uma ação ser puramente natural ou cultural. Para o filósofo, o fato de, normalmente, dormirmos à noite e ficarmos acordados de manhã envolve tanto componentes naturais/biológicos quanto culturais, e, assim, poderíamos pensar qualquer outro movimento existencial humano. Ou seja, a experiência vivida é sempre natural-cultural. No âmbito da psicopatologia, esta máxima é fundamental para uma compreensão dos processos de adoecimento a partir da fenomenologia de Merleau-Ponty.

As primeiras pesquisas em psicopatologia cultural foram marcadas por preconceitos e concepções deturpadas acerca das diferenças culturais. Os precursores desses estudos buscavam comparar e categorizar, hierarquicamente, as culturas. Apesar dos esforços nos últimos anos de tentar sair de uma postura etnocêntrica, entendemos que, ainda, há uma preponderância do modo de pensar ocidental nas estratégias de saúde mental (Fernando, 2011; Summerfield, 2008). O encontro de diferentes culturas (entre pesquisadores, entre pesquisador e sujeito colaborador, etc.) nas pesquisas em psicopatologia cultural tem refletido a necessidade de relativização do conhecimento, mas não de forma absoluta, possibilitando a concretização de uma investigação científica. Ou seja, deve-se considerar as questões subjetivas e culturais, mas sem abrir mão dos seus aspectos objetivos. É nesse sentido que a fenomenologia de Merleau-Ponty (1945/2000, 1948/1996, 1955/2006, 1961/2004, 1964/2007, 2001/2010, 1969/2010) se apresenta com notada contribuição, uma vez que resgata o movimento ambíguo entre os diversos polos da experiência humana, tais como subjetivo e objetivo, natural e cultural, dentre outros. Ao invés de sairmos inteiramente de um modelo para outro, trata-se de sabermos caminhar entre os dois.

Assim, Csordas (1990, 1993, 2008), Kirmayer (2006) e Kleinman (1988a) têm discutido a necessidade de relativizarmos as compreensões - ainda bastante ocidentalizadas - acerca da psicopatologia. Um exemplo são os manuais psiquiátricos, que propõem uma perspectiva universalizante, evidenciando um olhar unicamente objetivo para o corpo, desconsiderando seu caráter subjetivo, mundano e situacional. A fenomenologia de Merleau-Ponty (1945/2000, 1948/1996, 1955/2006, 1961/2004, 1964/2007, 2001/2010, 1969/2010), principalmente a partir da sua noção de corpo, pode contribuir com uma lente ambígua e contextualizada sobre os fenômenos psicopatológicos e sobre o corpo, superando as dualidades ainda existentes nos modos de compreensão dos processos de adoecimento, bem como em seus diagnósticos e tratamentos.

Em A Fenomenologia da Percepção, Merleau-Ponty (1945/2000) elabora a noção de "corpo próprio". Através desse conceito, a ideia de corpo não se configura como meramente físico, mas contempla o mundo em que esse corpo está: ao invés de termos um corpo, somos um corpo. No campo da fenomenologia, trata-se de uma importante distinção, que não tem correlato em português. Na língua alemã, Husserl (1954/1976) foi quem, inicialmente, ressaltou a diferença entre Körper e Leib, em que a primeira consistiria na noção de corpo físico, e a segunda, de corpo vivido, atrelado no mundo. A concepção de "corpo próprio", de Merleau-Ponty (1945/2000) deriva da noção de Leib, destacando a impossibilidade de o corpo ser pensado apenas sob a perspectiva física e objetiva. Em uma de suas obras mais tardias, Merleau-Ponty (1964/2007) introduziu a noção de "carne", que, também, não tem tradução exata para o português. Na língua francesa, o termo utilizado pelo filósofo é chair, uma compreensão de "carne" como elemento, quiasma, que permite o entrelaçamento com o mundo.

A despeito das distintas noções que apresenta ao longo das suas obras, a ideia de corpo em Merleau-Ponty mantém como eixo seu caráter ambíguo, como espaço da experiência homem-mundo, sendo sempre compreendido nessa relação. As noções de "corpo próprio" (Merleau-Ponty, 1945/2000) e "carne" (1964/2007) convergem para uma crítica à noção de corpo como meramente físico, presente na tradição científica. Para o filósofo, o corpo devia ser compreendido em seus aspectos objetivos e subjetivos. Essa tensa relação entre aspectos subjetivos e objetivos deve ser discutida, também, na psicopatologia cultural no tocante à escolha do método de pesquisa. Uma investigação científica a partir da contribuição da fenomenologia de Merleau-Ponty pode possibilitar um olhar mais ecumênico, sem priorizar métodos qualitativos ou quantitativos, compreendendo que o olhar que dirigimos aos fenômenos é sempre ambíguo. Priorizar um olhar subjetivo ou objetivo acerca da psicopatologia nos priva de compreender o fenômeno em suas distintas nuanças. Apesar de não estar embasado nessa fenomenologia, Kleinman (1988a; 1988b) categorizou três distintos modos de nos atermos às doenças mentais (sickness, illness e disease), tentando contemplar tanto aspectos subjetivos, como senso comum e experiência vivida, quanto objetivos, como epidemiologia e conceitos biomédicos. Esse pode ser considerado um ponto de possível convergência entre as pesquisas contemporâneas em psicopatologia cultural, e a fenomenologia da ambiguidade de Merleau-Ponty (1945/2000, 1948/1996, 1955/2006, 1961/2004, 1964/2007, 2001/2010, 1969/2010).

Devido a essa ambiguidade presente da proposta da fenomenologia de Merleau-Ponty, para além de uma simples escolha, a noção de liberdade implica um encontro do interior com o exterior, ou seja, do homem com o mundo, pois, ao mesmo tempo em que escolhemos algo no mundo, ele toca algo em nós. É desse modo que podemos pensar não apenas o engajamento a uma metodologia de pesquisa, mas à amostra, à procura do paciente e, também, à sua permanência em um tratamento, seja ele padronizadamente ocidental ou conivente com práticas culturais específicas: ao invés de uma simples escolha, trata-se de um posicionamento a partir da relação que o paciente e o profissional ou o pesquisador estabelecem com o mundo e com a sua cultura. Merleau-Ponty criticava uma ciência que pretendia uma total neutralidade científica e que se faça de forma descontextualizada, com um olhar de sobrevoo, afirmando que

é preciso que o pensamento de ciência - pensamento de sobrevoo, pensamento do objeto em geral - torne a se colocar num "há" prévio, na paisagem, no solo do mundo sensível e do mundo trabalhado tais como são em nossa vida, por nosso corpo, não esse corpo possível que é lícito afirmar ser uma máquina de informação, mas 
esse corpo atual que chamo meu, a sentinela que se posta silenciosamente sob minhas palavras e sob meus atos (Merleau-Ponty, 1961/2004, p. 14).

Merleau-Ponty resgatava, assim, a importância de considerarmos as experiências vividas daquele que pesquisa como parte do processo de fazer ciência. Ele criticava a ideia de que a ciência seria capaz de apreender os fenômenos em si mesmos, e de pretender neutralidade científica. Merleau-Ponty (1961/2004) argumentava que a ciência adotava um "pensamento de sobrevoo", quando as questões situacionais não eram consideradas, na ilusão de ser possível a neutralidade do pesquisador. A pesquisa, como qualquer outro fenômeno humano, apenas pode emergir do que ocorre entre pesquisador e mundo.

É importante considerarmos a liberdade, que é situada e engajada no pesquisador e no profissional de saúde. Precisamos estar cientes de que um tema de pesquisa, sua metodologia, seus questionários e amostras, bem como a prescrição de um tratamento, não são livremente escolhidos, mas trata-se de um posicionamento e de um engajamento diante de uma teia de relações entre pesquisador/profissional e seu mundo, sua cultura e sua situação concreta.

Para Kirmayer, Rousseau, Jarvis e Guzder (2008), há diferenças culturais não apenas entre sociedades distintas, mas entre grupos - as subculturas -, de profissionais de saúde e pesquisadores, por exemplo. Suas práticas e pesquisas, bem como os discursos decorrentes delas, não ocorrem da mesma forma, muito embora deva haver algo em comum para que a comunicação se estabeleça. Essa máxima pode ter notável contribuição nas equipes multidisciplinares, que devem reconhecer suas especificidades, ao mesmo tempo em que algo deve ser objetivo na sua expressão, permitindo que a comunicação se estabeleça. A linguagem, de acordo com Merleau-Ponty (1961/2004), é o que nos marca, nos diferencia e, ao mesmo tempo, o que nos une aos outros e ao mundo, sendo impossível ser expressa em sua totalidade, pois é dotada de uma opacidade que a limita em si mesma.

Merleau-Ponty (1961/2004) discutia a impossibilidade de tradução plena dos idiomas e de suas significações culturais. Ao afirmar que "dois gestos culturais só podem ser idênticos com a condição de se ignorarem mutuamente" (p. 102), o filósofo ressaltava que cada expressão se manifesta atreladamente a seu mundo, à sua cultura e à sua história, não podendo haver dois sentidos comuns em um mesmo gesto, a não ser que ignoremos os matizes que os constituem.

Merleau-Ponty (1964/2007) discutia, também, o tema da falta, outra questão que merece ser ponderada, pois está relacionada à impossibilidade de apreensão da verdade e dos fenômenos em si, em uma investigação científica. A cultura nos constitui e nos abre ao mundo, mas, ao mesmo tempo, nos limita. Na realização de uma pesquisa, bem como de qualquer outro modo de comunicação, haverá sempre uma falta, que é constitutiva, uma ausência sempre presente, um oco, algo que não se completa. Cézanne, através dos contornos pintados em seus quadros, retratou a opacidade do mundo, em que a possibilidade de apreensão e de compreensão do todo é sempre uma tentativa, inatingível.

Finalmente, uma lente a partir da fenomenologia de Merleau-Ponty, para a psicopatologia cultural, nos remete ao que deveria ser mais fundamental nos estudos da área: a máxima de que toda psicopatologia é cultural. Assim como toda experiência humana é culturalmente constituída, conforme afirma Kirmayer (2006), uma psicopatologia que não seja investigada em seus múltiplos contornos corre o risco de ser ingenuamente compreendida.

\section{Considerações Finais}

Uma compreensão da psicopatologia cultural que utiliza a lente da fenomenologia de Merleau-Ponty aponta para um novo olhar em torno de uma perspectiva que tem sido desenvolvida desde a década de 1940, quando as primeiras intervenções e pesquisas em psicopatologia cultural foram realizadas, bem como ocorreu a criação dos primeiros institutos e organizações da área (Fassin \& d'Halluin, 2007; Kirmayer, 2006). Muitas dessas pesquisas e intervenções limitavam-se a uma perspectiva comparativa e classificatória, mas hoje podemos perceber avanços nesse sentido (Gone \& Kirmayer, 2010). É nessa direção que a fenomenologia de Merleau-Ponty (1945/2000, 1948/1996, 1955/2006, 1961/2004, 1964/2007, 2001/2010, 1969/2010) pode constituir notável contribuição, rumo a um olhar crítico, permitindo sempre um movimento de questionamento e de reelaboração das compreensões e dos tratamentos das doenças mentais, pois permite aos pesquisadores e aos psicoterapeutas vinculados à psicopatologia cultural o reconhecimento do atravessamento de suas culturas nos fenômenos psicopatológicos, bem como, também, pela possibilidade de mudança diante do novo e do encontro com outras compreensões, dotadas de diferentes nuanças culturais sobre tais fenômenos.

A crítica, embasada na fenomenologia, ao modo de compreensão meramente objetivo da psicopatologia, não consiste na pretensão de substituir um modelo por outro, como escreveu Merleau-Ponty (1964/2007): "não como uma vitória do 'interior' sobre o 'exterior', do 'mental' sobre o 'material', mas como apelo à revisão de nossa ontologia, ao reexame das noções de 'sujeito' e 'objeto"” (p. 33). Ou seja, a grande contribuição da fenomenologia de Merleau-Ponty gira em torno de um novo olhar, uma nova compreensão, ressaltando a ambiguidade dos fenômenos, ao invés de se configurar em mais um posicionamento explicativo e cristalizado acerca da psicopatologia. Para além de atentar aos múltiplos contornos que constituem aquele que adoece, é fundamental que se considere, também, a experiência vivida e os múltiplos contornos daquele que cuida, seja ele médico, psicólogo, qualquer outro profissional, ou um amigo ou familiar. Nesse sentido, uma relação de ajuda pode não se concretizar como tal, sendo marcada por nuanças morais, muitas vezes enrijecidas.

Assumirmos uma postura ética, do cuidado com o outro, inspirada da fenomenologia de Merleau-Ponty, implica em nos posicionarmos diante do novo e daquilo que se apresenta a nós. Porém, trata-se de um posicionamento que é sempre engajado, uma escolha impossível de ser realizada em sua totalidade, uma vez que é na experiência - que se manifesta sempre através do corpo - que estamos 
em constante abertura (ou fechamento) ao outro. A partir de tal postura ética, é relevante compreendermos o modo como o mundo nos atravessa, para estarmos em relação com o outro e podermos compreender as suas e as nossas potencialidades e limitações. Afinal, como compreender o ser humano se não o consideramos, nem o compreendemos a partir do seu enraizamento no mundo, isto é, nas questões políticas, sociais, ideológicas e culturais, dentre outras, que o constituem? Assim, acreditamos que a lente baseada na fenomenologia de Merleau-Ponty pode contribuir para um olhar ético, crítico e contextualizado acerca dos fenômenos psicopatológicos.

Concluímos, por meio dessa lente, que a grande contribuição da fenomenologia de Merleau-Ponty para a psicopatologia cultural é recuperar a noção primordial de que toda psicopatologia é cultural. Compreendendo-a em seus múltiplos contornos, deixaremos de adotar uma postura ingênua com relação à psicopatologia. Como nos lembra o filósofo, nossa compreensão é sempre limitada e sempre se abre ao novo. Assim, convidamos outros pesquisadores a utilizar essa lente, reaprendendo a perceber e compreender as várias experiências psicopatológicas que proliferam na contemporaneidade.

\section{Referências}

Alvim, M. (2011). A ontologia da carne em Merleau-Ponty e a situação clínica na Gestalt-terapia: entrelaçamentos. Revista da Abordagem Gestáltica, XVII(2), 143-151.

APA - American Psychiatric Association. (2000). Diagnostic and statistical manual of mental disorders: DSM-IV-TR. Washington, DC: Author.

APA - American Psychiatric Association. (2012). DSM-V Development. Retrieved from http://www.dsm5.org/Pages/ Default.aspx

Becks-Malorny, U. (2007). Cézanne. Köln: Taschen.

Coelho Jr., N. (2003). Da intersubjetividade à intercorporeidade: contribuições da filosofia fenomenológica ao estudo psicológico da alteridade. Psicologia - SP, 14(1), 185-209.

Csordas, T. (1990). Embodiment as a Paradigm for Anthropology. Ethos, 18(1), 5-47.

Csordas, T. (1993). Somatic Modes of Attention. Cultural Anthropology, 8(2), 135-156.

Csordas, T. (2008). Corpo/significado/cura. Porto Alegre: Editora da UFRGS.

Devereux, G. (1977). Essais d'ethnopsychiatrie générale. Paris: Gallimard.

Dupont, P. (2010). Vocabulário de Merleau-Ponty. São Paulo: Martins Fontes.

Fassin, D., \& d'Halluin, E. (2007). Critical Evidence: The Politics of Trauma in French Asylum Policies. Ethos, 35(3), 300-329.

Felder, A. \& Robbins, B. (2011). A cultural-existential approach to therapy: Merleau-Ponty's phenomenology of embodiment and its implications for practice. Theory Psychology, 21(3), 355-376.

Fernando, S. (2011). A 'global' mental health program or markets for Big Pharma? Open Mind, 22.
Gone, J., \& Kirmayer, L. (2010). On the wisdom of considering culture and context in psychopathology. In T. Millon, R. Krueger, \& E. Simonsen (Eds.), Contemporary Directions in Psychopathology: Scientific Foundations of the DSM-V and ICD-11 (pp. 72-96). New York: Guilford Press.

Husserl. E. (1976). La crise des sciences européenes et la phénoménologie transcendantale. Gallimard. (Trabalho original publicado em 1954)

Kirmayer, L. (2006). Cultural psychiatry in historical perspective. In D. Bhugra, K. Bhui (Eds.), Textbook of Cultural Psychiatry (pp. 3-19). Cambridge: Cambridge University Press.

Kirmayer, L., Rousseau, C., Jarvis, G., \& Guzder, J. (2008). The cultural context of clinical assessment. In A. Tasman, J. Lieberman, \& J. Kay (Eds.), Psychiatry (3 ed., pp. 54-66). New York: John Wiley \& Sons.

Kleinman, A. (1988a). Rethinking psychiatry: from cultural category to personal experience. New York: Free Press.

Kleinman, A. (1988b). The illness narratives: suffering, healing and the human condition. USA: Basic Books.

Kleinman, A., \& Good, B. (1985). Culture and depression: studies in the anthropology and cross-cultural psychiatry of affect and disorder. Berkeley and Los Angeles, California: University of California Press.

López, S., \& Guarnaccia, P. (2000). Cultural psychopathology: uncovering the social world of mental illness. Annual Review of Psychopathology, 51, 571-598.

Matthews, E. (2010). Compreender Merleau-Ponty. Petrópolis. Vozes.

Merleau-Ponty, M. (1996). Sens et non-sens. Éditions Gallimard. (Trabalho original publicado em 1948)

Merleau-Ponty, M. (2000). A fenomenologia da percepção. São Paulo: Martins Fontes. (Trabalho original publicado em 1945)

Merleau-Ponty, M. (2004). O olho e o espírito. São Paulo: Cosac \& Naify (Trabalho original publicado em 1961)

Merleau-Ponty, M. (2006). As aventuras da dialética. São Paulo: Martins Fontes (Trabalho original publicado em 1955)

Merleau-Ponty, M. (2006). Psicologia e pedagogia da criança. São Paulo: Martins Fontes (Trabalho original publicado em 2001).

Merleau-Ponty, M. (2007). O visivel e o invisivel. São Paulo: Perspectiva. (Trabalho original publicado em 1964)

Merleau-Ponty, M. (2010). La prose du monde. In M. MerleauPonty (Ed.), Oeuvres. (pp. 1423-1540). Éditions Gallimard. (Trabalho original publicado em 1969)

Moreira, V. (2009). Clínica humanista-fenomenológica: estudos em psicoterapia e psicopatologia crítica. São Paulo: Annablume.

Moreira, V. (2010). Possíveis contribuições de Husserl e Heidegger para a Clínica Fenomenológica. Psicologia em Estudo, Maringá, 15(4), 723-731.

Moreira, V. \& Sloan, T. (2002). Personalidade, ideologia e psicopatologia crítica. São Paulo: Escuta.

Moreira, V. \& Telles, V. (2012). A noção de liberdade no pensamento de Merleau-Ponty: contribuições para a psicoterapia. In A. Tatossian, \& V. Moreira (Eds.), Clínica do Lebenswelt: Psicoterapia e psicopatologia fenomenológica (pp. 231-242). São Paulo: Escuta.

Sam, D. L., \& Moreira, V. (2012). Revisiting the Mutual Embeddedness of Culture and Mental Illness. Online Readings in Psychology and Culture, Unit 10. Retrieved from http:// scholarworks.gvsu.edu/orpc/vol10/iss2/1 
Summerfield, D. (2008). How scientifically valid is the knowledge base of global mental health? BMJ, 336, 991-995.

Tatossian, A. (2001). Cultura e psicopatologia: um ponto de vista fenomenológico. Revista Latinoamericana de Psicopatologia Fundamental, IV(3), 137-144.

Tatossian, A., \& Moreira, V. (2012). Clínica do Lebenswelt: Psicoterapia e psicopatologia fenomenológica. São Paulo: Escuta.
Recebido em 25.04.2013

Primeira decisão editorial em 29.07.2013

Versão final em 13.09.2013

Aceito em 17.10.2013

\section{Congresso Brasileiro de Psicologia da Saúde}

$31 / 07$ a $02 / 08 / 2014$

Taubaté - SP

Universidade de Taubaté

www.abpsa.com.br 